\title{
Development partner support to the health sector at the local level in Morogoro region, Tanzania
}

\author{
GASTO M. FRUMENCE ${ }^{1}$, JOY J. CHEBET' ${ }^{2,3}$, JENNIFER A. CALLAGHAN-KORU ${ }^{2,4}$, IDDA MOSHA ${ }^{5}$, DERECK \\ CHITAMA ${ }^{1}$, JAPHET KILLEWO 5 and PETER J. WINCH ${ }^{2}$ \\ ${ }^{1}$ Department of Development Studies, Muhimbili University of Health Sciences, Dar es Salaam, Tanzania \\ ${ }^{2}$ Department of International Health, Johns Hopkins Bloomberg School of Public Health, Baltimore, MD, USA \\ ${ }^{3}$ Department of Health Promotion Sciences, Mel and Enid Zuckerman College of Public Health, University of \\ Arizona, Tucson, AZ, USA \\ ${ }^{4}$ Department of Sociology, Anthropology, and Health Administration and Policy, University of Maryland- \\ Baltimore County, Baltimore, MD, USA \\ ${ }^{5}$ Department of Behavioral Sciences, School of Public Health and Social Sciences, Muhimbili University of Health \\ and Allied Sciences, Dar es Salaam, Tanzania \\ ${ }^{6}$ Department of Biostatistics and Epidemiology, Muhimbili University of Health and Allied Sciences, Dar es \\ Salaam, Tanzania
}

\begin{abstract}
Background: The Tanzanian health sector receives large amounts of funding from multiple international development partners to support a broad range of population-health interventions. However, little is known about the partners' level of commitment to sustain funding, and the implications of uncertainties created by these funding mechanisms. This study had the following objectives: 1) To present a theoretical model for assessing funding commitments by health development partners in a specified region; 2) to describe development partner funding commitments against this framework, using a case study example of Morogoro Region, Tanzania; and 3) to discuss policy considerations using this framework for district, regional and national level.

Methods: Qualitative case study methodology was used to assess funding commitments of health-related development partners in Morogoro Region, Tanzania. Using qualitative data, collected as part of an evaluation of maternal and child health programs in Morogoro Region, key informants from all development partners were interviewed and thematic analysis was conducted for the assessment.

Results: Our findings show that decisions made on where to commit and direct funds were based on recipient government and development partner priorities. These decisions were based on government directives, such as the need to provide health services to vulnerable populations; the need to contribute towards alleviation of disease burden and development partner interests, including humanitarian concerns. Poor coordination of partner organizations and their funding priorities may undermine benefits to target populations. This weakness poses a major challenge on development partner investments in health, leading to duplication of efforts and resulting in stagnant disease burden levels.

Conclusion: Effective coordination mechanisms between all stakeholders at each level should be advocated to provide a forum to discuss interests and priorities, so as to harmonize them and facilitate the implementation of development partner funded activities in the recipient countries.
\end{abstract}

Keywords: funding commitment, development partner, health sector, Tanzania

\section{Introduction}

Research on funding commitments mechanisms typically focus on development partner contributions toward the implementation of health-related interventions in a given country (Chen et al., 2012). In the last two decades, there has been a tremendous increase of allocation of funding to support social and economic development efforts in Sub-Saharan African countries (Schieber et al., 2006). Health is one of the sectors that receives substantial foreign funds from multiple development organizations to support the implementation of a broad range of healthrelated interventions (Michaud \& Murray, 1994). In Tanzania, development partners have been shown to implement overlapping health interventions, making it challenging to attribute health outcomes to specific interventions (Rotarou \& Ueta, 2009). Furthermore, health interventions in 
developing countries have been implemented based on donor preference, rather than specific needs of the recipient countries (Thompson et al., 2007).

Tanzania, both pre and post-reform, received the largest foreign aid in Sub-Saharan Africa (Tripp, 2012). The country receives aid in the form of bilateral cooperation, where funds are directly disbursed to the government, or through projects and multilateral cooperation conducted by the United Nations (UN) agencies. Additionally, Tanzania receives external support through support to the general budget, support through pooled basket funding, where different development partners contribute money into one basket, and support through direct project funding (Zinnen, 2010).

A multi-country study conducted in Tanzania, Brazil and Peru showed that factors, other than community health needs, were considered when deciding where to implement an Integrated Management of Childhood Illness (IMCl) intervention. These factors included availability of suitable training sites, proximity to the capital city, availability of well-motivated health managers and well-functioning health systems (Victora et al., 2006). Another study reported that community-based interventions fail because beneficiaries perceive the program as being imposed on them by outsiders, or are implemented in environments that are inappropriate, or are lacking local management and governance structures (Conyers \& Mellors, 2005).

Several models have been proposed to show how aid should be allocated in health and other sectors (Feeny \& McGillivray, 2008). Early studies on aid allocation suggested a dichotomy between recipient needs and development partner interest models, and found the latter dominated the former in allocating aid to the recipient countries (McKinley \& Little, 1979). In Maizels and Nissanke's recipient-needs model, aid is allocated as compensation for deficits to the locally generated resources. On the other hand, in the development partner interest model, aid allocation aims at serving the partners' interests in terms of political and/or security, trade and investments' interests (Maizels \& Nissanke, 1984). Later studies have added two more components-human rights and recipient-country institutions - to the McKinley and Little dichotomy. Neumayer (2003) suggests that in bilateral aid, countries which observe civil and political rights, as well as respecting personal integrity rights tend to get more aid. For multilateral aid, efforts made by the recipient governments to improve the respect for civil/political rights seem to carry more weight on aid allocation (Neumayer, 2003).

From these models, development partners and aid recipient governments are the main stakeholders in deciding where resources for health interventions should be allocated. However, lack of a clear coordination mechanism among funding decision-makers, places a substantial barrier to the successful implementation of health interventions (Schieber et al., 2006). Therefore the objectives of this paper are: 1) to present a theoretical model for assessing partner funding commitments in health in a region; 2) to describe the partner funding commitments against this model using a case example of Morogoro Region, Tanzania; and 3) to discuss policy considerations using this model for district, regional and national level.

\section{Materials and Methods}

\section{Study setting}

This study was conducted in six administrative districts of Morogoro Region, namely; Morogoro rural, Mvomero, Kilosa, Ulanga, Kilombero and Morogoro municipality (the only urban district in the region). Morogoro is the second largest and sixth most populous of Tanzania's 26 regions with a population of 2.22 million people (URT, 2013). In this region, Kilosa district had the large population and big burden of diseases while Ulanga district has little population and Morogoro municipality has low burden of diseases compared with other districts. 


\section{Study design and selection of participants}

A partner funding and allocation assessment was conducted as part of a larger evaluation of Maternal and Child Health $(\mathrm{MCH})$ program in Morogoro Region. Data on all partners working in the areas of Maternal, New-born and Child Health $(\mathrm{MNCH})$ and HIV were collected in Morogoro Region as part of a partner mapping exercise conducted to provide contextual data for a larger program evaluation study.

Data for this study were collected from two respondent groups: representatives from development partner organizations, including international and national nongovernmental organizations (NGOs), community-based organizations (CBOs), consortia and alliances; and District Reproductive and Child Health (DRCH) coordinators from all the 6 districts in Morogoro Region, as representatives for the Council Health Management Team (CHMT). The development partner organizations were eligible to participate in the study if: they were an NGO, had previously or are currently working in at least one of the 6 districts in the Morogoro region and activities carried out by the partner are focused in the area of $\mathrm{MNCH}$, malaria or HIV/AIDS. An initial list of organizations was informed by previous research activities and discussions with the Regional Medical Officer (RMO). More organizations were identified through a snowball sampling strategy, where recruited organizations were requested to identify other organizations working in $\mathrm{MNCH}$ in Morogoro region. Twenty eligible organizations were identified and first contacted via recruitment email, which described the research goals and objectives and requested their participation. In all 6 districts, Reproductive and Child Health $(\mathrm{RCH})$ coordinators were selected because of their experience in $\mathrm{MNCH}$ activities/interventions taking place in their districts.

\section{Data collection}

We conducted in-depth and structured interviews with selected study participants. The questionnaire included open-ended questions that sought to gain a deeper understanding of a number of activities within eight program areas that development partners allocate funds to the health sector in Morogoro region. These program areas included: maternal health, family planning, other reproductive health services, neonatal health, child health, maternal and child HIV, malaria, and other HIV program areas. Furthermore, the questionnaire included questions about the length of time development partners have allocated funds in the region, their rationale for allocating funds in specific areas and how they coordinate with other partners and the CHMTs. Data were collected by researchers between June and October 2012 using instruments which had been designed and pretested (Radhakrishna, 2007). The location of the interviews was dependent on the office location of the partner organizations. All interviews were either conducted in person or over the phone. A total of 20 development partner organizations and 6 $\mathrm{RCH}$ coordinators were successfully interviewed. During the interview with development partners and CHMT members, researchers filled the questionnaires electronically and sent the electronic completed questionnaire to each respondent to review accuracy and completeness.

\section{Ethical consideration}

This study obtained ethical clearance from Muhimbili University of Health and Allied Sciences ethical Review Board (MUHAS IRB Reference No: MU/RP/AED Vol XIII) as well as John Hopkins University Institutional Review Board (JHU IRB No: 00003296). Permission for conducting the study was also obtained from the regional and district authorities of Morogoro region. Before collecting data, all participants were asked to sign informed consent form, indicating the objectives of the study, procedures to be followed in data collection risks and benefits of participation and confidentiality of the data. 


\section{Data analysis}

Thematic analysis was employed to assess emerging themes, including integrating provider interests, recipient needs and coordination mechanisms. Tables were used to generate a summary of partners' activities in each district, which allow the researchers to compare which districts have more funding from development partners than others.

\section{Results}

\section{Partner activities by programmatic area}

Maternal and child HIV was the program area with the most active partners, while neonatal health had the least active partners. There was a wide variation in the types of activities being implemented by partners. Within each program area, partners reported conducting different types of interventions, from interventions at community level including health education, provision of community-based services through volunteers or paid Community Health Workers ( $\mathrm{CHWs}$ ) and through facilities (training of health workers, provision of equipment and supplies).

Out of 40 activities reported by partner organizations, only six activities (15\%) involved the direct provision of an intervention to beneficiaries. These activities included outreach services for Family Planning (FP); health education; Community-based assessment and referral for mothers and children; distribution of family planning commodities; home-based care for people living with HIV/AIDs; and Distribution of insecticide Treated Nets (ITNs) and Provision of Voluntary Counselling and Treatment (VCT) services.

Table 1. Number of contributing partners by Program Area and Activity

\begin{tabular}{|c|c|c|c|}
\hline Program Area & $\begin{array}{ll}\text { No. of } \\
\text { partner }\end{array}$ & Specific Activities & $\begin{array}{l}\text { No. of } \\
\text { partner* } \\
*\end{array}$ \\
\hline \multirow{6}{*}{$\begin{array}{l}\text { Maternal } \\
\text { Health } \\
(15 \%) \text { of all } \\
\text { activities) }\end{array}$} & \multirow[t]{6}{*}{8} & Development of national guidelines and training materials & 1 \\
\hline & & Community Outreach and Education & 4 \\
\hline & & Community-based assessment and referral & 1 \\
\hline & & Training Providers & 5 \\
\hline & & Renew facility infrastructure & 1 \\
\hline & & Provide equipment and supplies to facilities & 1 \\
\hline \multirow{4}{*}{$\begin{array}{l}\text { Family } \\
\text { Planning } \\
\text { (10\% of all } \\
\text { activities) }\end{array}$} & \multirow[t]{4}{*}{9} & Health education & 5 \\
\hline & & Distribute FP commodities through CBDs/CHWs & 4 \\
\hline & & Train health workers & 3 \\
\hline & & Provide equipment & 2 \\
\hline \multirow{5}{*}{$\begin{array}{l}\text { Other } \\
\text { Reproductive } \\
\text { Health } \\
(12.5 \% \text { of all } \\
\text { activities) }\end{array}$} & \multirow[t]{5}{*}{8} & Development of national guidelines and training materials & 1 \\
\hline & & Health Education & 5 \\
\hline & & Research study & 1 \\
\hline & & Training providers & 2 \\
\hline & & Provide equipment and supplies & 1 \\
\hline \multirow{5}{*}{$\begin{array}{l}\text { Neonatal } \\
\text { Health* } \\
\text { (12.5\% of all } \\
\text { activities) }\end{array}$} & \multirow[t]{5}{*}{5} & Health education and community outreach & 3 \\
\hline & & Research study & 1 \\
\hline & & Training health providers & 3 \\
\hline & & Providing equipment to facilities & 2 \\
\hline & & Infrastructure renewal & 2 \\
\hline \multirow{3}{*}{$\begin{array}{l}\text { Child Health* } \\
(15 \% \text { of all } \\
\text { activities) }\end{array}$} & \multirow[t]{3}{*}{9} & Community outreach and education & 5 \\
\hline & & Community-based assessment and referral & 1 \\
\hline & & Research study & 1 \\
\hline
\end{tabular}




\begin{tabular}{|c|c|c|c|}
\hline & & Training facility health providers & 3 \\
\hline & & Infrastructure renewal & 1 \\
\hline & & Provision of equipment and supplies to facilities & 1 \\
\hline \multirow{6}{*}{$\begin{array}{l}\text { Maternal and } \\
\text { child HIV (15\% } \\
\text { of all activities) }\end{array}$} & \multirow[t]{6}{*}{12} & Home-based care through community volunteers & 4 \\
\hline & & Health education and community outreach & 5 \\
\hline & & Voluntary counselling and testing & 1 \\
\hline & & Training facility providers & 6 \\
\hline & & Quality improvement activities & 1 \\
\hline & & Provision of equipment and supplies to facilities & 1 \\
\hline \multirow{3}{*}{$\begin{array}{l}\text { Malaria }(7.5 \% \\
\text { of all activities) }\end{array}$} & \multirow[t]{3}{*}{10} & Community outreach and health education & 6 \\
\hline & & Distribution of ITNs & 3 \\
\hline & & Training facility health providers & 1 \\
\hline \multirow{5}{*}{$\begin{array}{l}\text { Other } \\
(12.5 \% \text { of } \\
\text { activities) }\end{array}$} & \multirow[t]{5}{*}{7} & Home-based care through community volunteers & 4 \\
\hline & & Provision of VCT & 2 \\
\hline & & Orphan and vulnerable child services & 2 \\
\hline & & Research study & 1 \\
\hline & & Training of health providers on VCT & 3 \\
\hline
\end{tabular}

*Excluding HIV activities related to new-born/child health, which are counted under "maternal and child HIV"; **There are partners doing more than one activity in a program area.

\section{Funding commitments across the districts}

Seven partners reported working in all five rural districts of Morogoro Region. Out of these, five of the partners also covered Morogoro Municipal District (the only one urban district in the Region). The remaining 13 partners were not covering the whole Region. Morogoro Rural and Mvomero had the highest levels of partner funding commitments when compared with other districts. Both districts have community-level activities for HIV/AIDS and family planning as well as quality improvement activities at facility level. Kilosa had the lowest partner funding commitments, with only 2 region-wide partners implementing interventions on HIV training and provision of medical supplies. Kilombero and Ulanga had relatively high $\mathrm{MNCH}$ funding commitments, compared with other districts, due to the presence of two major projects: demographic surveillance and the establishment of new health cadre known as community health agents (CHAs).

In all the six districts of Morogoro region, the majority of the partner organizations made decisions on where to commit funds based on directives given to them by the aid recipient government (dimension III) (Table 2). In all six districts, saving vulnerable groups particularly women, poor and under-five children was also another main reason why partners' organizations commit funds in these areas. The presence of hard to reach areas in four districts was also reported by partners' organization as one of the factors for committing funds in these districts. The study findings showed that development partners' interest (dimension II in Table 1, aid provider interest) was also the basis for making decision to commit funds in all six districts.

Table 2. Number of partners in each district and the dimension used to make decisions on health funding commitment

\begin{tabular}{|c|c|c|c|c|c|c|}
\hline \multirow[t]{2}{*}{ Dimension } & \multicolumn{6}{|c|}{ Number of partners in each district } \\
\hline & Ulanga & Kilosa & Mvomero & Kilombero & $\begin{array}{l}\text { Morogoro } \\
\text { rural }\end{array}$ & $\begin{array}{l}\text { Morogoro } \\
\text { Urban }\end{array}$ \\
\hline Dimension I (aid providers' interest) & 2 & 2 & 2 & 2 & 2 & 2 \\
\hline \multicolumn{7}{|l|}{ Dimension II (Aid Recipient needs): } \\
\hline Government directives & 4 & 3 & 4 & 4 & 4 & 3 \\
\hline Vulnerable groups & 1 & 1 & 1 & 1 & 1 & 1 \\
\hline
\end{tabular}




\begin{tabular}{|c|c|c|c|c|c|}
\hline Hard to reach areas & 1 & 1 & 0 & 1 & 1 \\
\hline Community health needs & 1 & 1 & 0 & 1 & 1 \\
\hline Avoid duplication of activities & 1 & 1 & 1 & 0 & 1 \\
\hline Burden of diseases & 0 & 0 & 1 & 0 & 2 \\
\hline Collaborating with local partner & 1 & 0 & 0 & 1 & 0 \\
\hline Population size & 1 & 0 & 0 & 1 & 0 \\
\hline Geographical size/long distance & 1 & 0 & 0 & 1 & 0 \\
\hline Build human resource capacity & 1 & 0 & 0 & 1 & 0 \\
\hline Inadequate infrastructures & 1 & 0 & 0 & 1 & 0 \\
\hline Demographic Surveillance & 1 & 0 & 0 & 1 & 0 \\
\hline Military camps with health facilities & 0 & 1 & 0 & 0 & 1 \\
\hline Experience from previous work & 0 & 0 & 1 & 0 & 1 \\
\hline
\end{tabular}

\section{Coordination of partners' funding commitments in health}

We obtained information about coordination of partners' organizations' funding commitments from the $\mathrm{RCH}$ coordinators and programme managers of partner organizations. Findings from $\mathrm{RCH}$ coordinators show that there are different ways through which CHMT coordinates health interventions implemented by various partner organizations at the district level. They reported that partners are supposed to report to district authority when they conduct any activity in the district; they are invited to participate in their annual planning meetings where they share information about the types of interventions they implement in the districts and report if there are any other plans for the new interventions in the following calendar year. For the reproductive health, child health, neonatal, prenatal and maternal health, the districts have joint audit meeting with partner organizations every 6 months. According to district $\mathrm{RCH}$ coordinators the purpose of coordinating partners' funding commitments in health is to reduce duplication of efforts and to ensure equity in service provision at the district. However, there are several identified barriers for smooth coordination of partners' funds at the district level. Although all partners are invited to attend annual and biannual meetings, not all of them are able to attend these meetings making it difficult for the CHMT to coordinate their activities. Other partner organizations have different planning and financial cycles that conflict with those of the district. For instance the planning and financial cycle of 4 partner organizations out of 5 in Morogoro rural district starts in January while the district planning cycle starts in July each year. Such differences in planning cycles tend to lead to some organizations opting not to provide their plans for the year.

Respondents from partner organization reported several ways on how they coordinate their activities both among themselves and with district authorities. Of the 20 organizations participated in the study $12(60 \%)$ said that they participate in the national, regional and district meetings that bring together different partners to discuss various interventions taking place in the country. All four organizations, which receive funding from the same source have established a network that brings them together to share experience and barriers facing the implementation of their activities.

Our findings show that 6 organizations (30\%) usually hold annual meetings and invite organizations with similar activities in the same districts. A total of $4(20 \%)$ of the partner organizations said that they also participate in international forums, which bring together different stakeholders working in specific interventions from different countries to share experiences and learn from one another. Furthermore, 6 (30\%) organizations also reported that coordination has helped them to work together in areas where other organizations are more competent than others especially in conducting training and advocacy programmes.

Eight organizations (40\%) reported that by attending regular meetings with other partners, they share information on what they are doing, which helps them to avoid duplication of activities by partners. However, 5 organizations (25\%) reported that occasionally they participate in the national forums which bring together different partners, but they claimed that 
coordination of partner activities has not yet been done successfully as there are still duplications of activities by partners.

\section{Discussion}

This study sought to explore reasons why development partners commit funds in certain health interventions in specific areas over others. Findings from this study have shown that two rural based districts (Morogoro rural and Mvomero) have the highest level of partner funding commitments targeting community-level activities for HIV/AIDS and family planning as well as quality improvement activities at facility level. This implies that the two districts received more allocation of resources compared to other districts in Morogoro region. Similarly the findings show that Kilombero and Ulanga districts had received relatively more partner funds in Maternal and Newborn Health $(\mathrm{MNH})$ compared to other districts in the region.

We found the decisions made by most of the partner organizations on where to commit funds were based on the government directives. The Government of Tanzania, which is the recipient of the health funding commitments from different international organizations, was responsible for directing these organizations on which districts they should implement various health interventions. Other decisions on where to commit funds based on other important determinants of health needs included the need to provide health services to most vulnerable populations in the community namely; women and under five children and hard to reach remote areas; and the need to contribute towards alleviating burden of diseases. We also found that some partner organizations committed funds in districts with large size populations as well as big geographical coverage. Development partners' interest was observed in a few partner organizations as a deciding factor on which interventions and districts to commit funds in the health sector.

Findings from this study suggest that partners involved the government in deciding on the location where they should channel their resources. It appears from the partners' perspective that the government directives regarding where to commit funds have been an important factor in determining the allocation of funds in the health sector. It is worth noting that areas that received partner funds included the maternal and child health areas, which have been prioritized in the National Road Map Strategic Plan, which aimed at accelerating reduction of MNCH deaths in Tanzania between 2008 and 2015. Some of the identified priority areas in the strategic plan, which received partner funds included family planning, prevention of malaria for pregnant women and under-five children, increased Prevention of Mother to Child Transmission (PMTCT) of HIV, increased number of antennal care visits and increased CHW programs at the community level (URT, 2008).

However, development partners and the government sometimes shift responsibility between each other, with regard to failure to decide where interventions and resources should be directed. For instance on one hand, the Ministry of Health had criticized development partners for taking their own route in committing funding to certain project development and implementation, while on the other hand, development partners criticized the Ministry of Health for not providing direction in project development and management (Mapunda, 2003). In 1993 the Ministry of Health identified factors, which were revised in 2003, to guide the allocation of financial resources including resources from the development partners. The identified factors, which apply to both vertical and horizontal programmes focus on achieving equity in resource allocation in the country. The allocation of resources is now based on districts or areas with large populations, high poverty level, more geographical coverage and high burdens of diseases (Mapunda, 2003).

The findings show that there are three reasons used by development partner organizations in committing funds to the districts. First to serve the vulnerable population groups such as women and children; second to support provision of health services in the hard to reach 
areas where majority of poor people live and third to achieve partners' own interests. A study on the determinants of aid in the post-cold war era (Bandyopadhyay \& Wall, 2006) concluded that as opposed to aid during the cold war era, which emphasized low per capita income when committing funds in health, in the post-cold war era, funding commitment should generally respond to infant mortality (representing burden of disease), government effectiveness and human rights. This indicates that apart from burden of diseases, partner organizations have other dimensions, which they consider when deciding where to commit funds as opposed to recipient governments. Piva \& Dodd (2009) reported concerns that priorities on where to commit funds in the health sector have been increasingly determined at global and regional levels rather than at the recipient country level.

The findings have shown that both at the national and district level, there was no reliable coordination of partner organization activities, recipient government interests or district council priorities respectively. Buse (1999) reported similar findings showing that in many low and lowermiddle income countries, development partner activities are uncoordinated; and in some cases where there are efforts to coordinate them, the coordination is mainly done by the development partners themselves while recipient governments manage a small part of committed funds. This is contrary to the Paris Declaration, which called for proper coordination of official development assistance (OECD, 2005) and the OECD-High Level Forum on Harmonization (HLF), which called for improving the management of official aid so as to increase efficient use of the resources (OECD, 2006). The declaration on Harmonization emphasized further that development partner support should be aligned with the identified priorities of the recipient countries and that there should be efforts to rationalize recipient countries' led efforts to development partner procedures, practices and standards to form the basis of coordination (Lawson, 2012). The coordination of foreign aid particularly in the health sector in Tanzania is even more important given the high dependency of foreign assistance which in 2009 and 2010 was 40\% (Afnan-Holmes et al., 2015; URT, 2009)

The findings for this study show that there is no needs-based coordination of committed funds both at the national and district level, which has necessitated us to propose a theoretical model (Figure 1) that policy analysts and programme managers can use to analyse partner supported activities in the health sector. This model seeks to integrate the needs of development partners, implementing agents and recipients, with a coordination mechanism. It draws from two dominant models in the literature: partner interest model (which includes implementing agents' needs) and recipient (government) needs model). We propose the integration of these models with the priorities of the district council (Maizels \& Nissanke, 1984; McKinley \& Little, 1979; Neumayer, 2003; Schieber et al., 2006). This integration will facilitate successful implementation of health interventions if there will be clearly defined coordination mechanisms among all stakeholders. Therefore we propose aid coordination mechanisms as a central dimension to be considered when analyzing funding commitments in the health sector by the development partners.

The proposed model suggests that there should be coordination mechanisms at three levels: the global level where development partner organizations and implementing agencies coordinate their development assistance to the developing countries so as to avoid having a number of projects in certain countries and in specific sectors as compared to others. This is in line with what the Paris declaration recommended (OECD, 2005). At the national level, our theoretical model (Figure 1) proposes the integration of partner organizations' priorities with the needs of the aid recipient governments so that the partners' activities should reflect the recipient government priorities. More importantly, the proposed theoretical adds to what Lawson (Lawson, 2012) has reported about harmonization of partner activities and those of recipient government priorities and suggests that the partner activities including vertical programmes and the national priorities should be coordinated together with the district councils' priorities. 


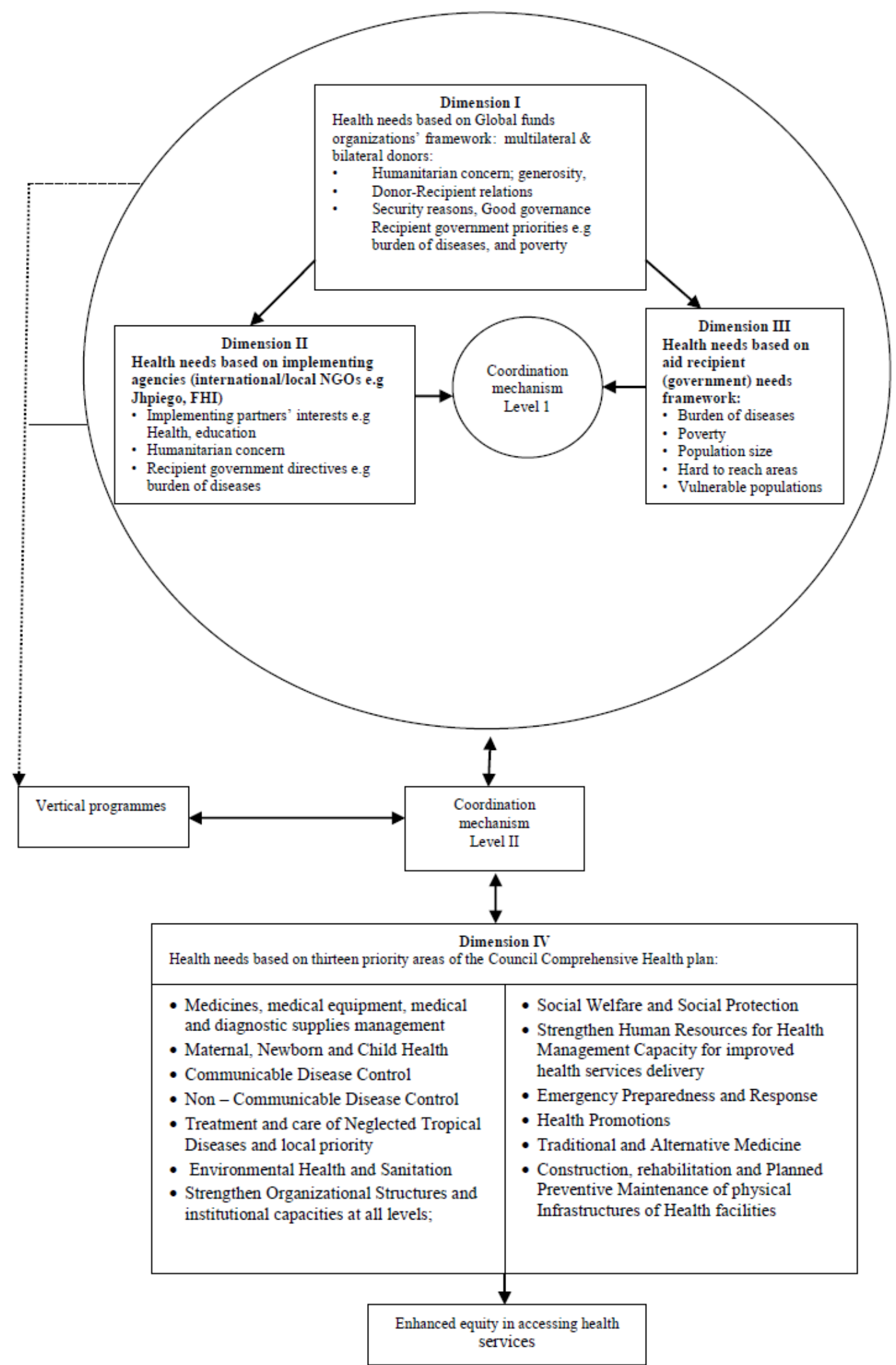

Figure 1: Proposed theoretical model for assessing and coordinating various stakeholders' needs and development partners' funding commitments in health

According to Lawson there are several reasons why coordination of development partners' funding commitments is important. Among others include avoidance of providing more assistance in one area while a neighbouring area has no similar support and duplication of 
activities in one area while there are areas requiring the same interventions. In addition there is undermining of development objectives and goals of a particular society because of lack of harmonization among interests of participating stakeholders and increased administrative burden on the recipient governments. This is due to the fact that development partners' activities have more accounting and oversight demands such as preparation and submission of regular technical and financial reports (Lawson, 2012).

Therefore coordination of partner funds at the district level is vital given the fact that under decentralized health systems in Tanzania, district authorities are responsible for setting health priorities in the areas under their jurisdiction and that if there will be good coordination of the development partner activities, national level needs and district council priorities, then such coordinated efforts will lead into the overall goal of achieving the health outcomes including enhancing equity in accessing health services particularly among the poor population majority of which are living in the rural areas in Tanzania (Figure 1). Other population health outcomes expected to benefit from putting in place good coordination of the committed funds by different partners may include reduction of infant mortality rate, reduction of maternal mortality rates, reduction of HIV transmission and increased life expectancy to the majority of poor people living in the hard to reach areas. According to WHO Framework for National Health Policies, Strategies and Plans, the decentralized health systems may allow not only the interpretation of national strategic plans at the local level where operations of health activities take place but it also allows the incorporation of plans made at the lower level governance structures aiming at improving the health status of the population in their respective local areas (WHO, 2010).

Table 3 shows that the coordination of development partner's funding commitments in health should ensure that at the global level, the interests/needs of the development partners are well coordinated with the aid recipients' government (Schieber et al., 2006; Semali \& Minja, 2005; Shiffman, 2006). At the district level where health interventions take place, the coordination of aid allocation should be guided by the Comprehensive Council Health Plan guideline, which has prioritized areas requiring interventions during the district annual health planning (URT 2011)

Table 3. Dimensions considered when allocating aid/committing funds in health interventions

\begin{tabular}{|c|c|c|}
\hline Dimension & Factors & Explanation \\
\hline \multirow{6}{*}{$\begin{array}{ll}\text { Dimension I: } & \text { Global } \\
\text { level } & \\
\text { Health needs } & \text { based } \\
\text { on global funds } \\
\text { organizations' } \\
\text { framework }\end{array}$} & $\begin{array}{l}\text { Humanitarian concern/ } \\
\text { generosity }\end{array}$ & $\begin{array}{l}\text { Funder are motivated by a humanitarian reason to } \\
\text { Promote development and alleviate needs, especially aid focusing } \\
\text { on poverty alleviation }\end{array}$ \\
\hline & $\begin{array}{l}\text { Donor-Recipient } \\
\text { relations }\end{array}$ & $\begin{array}{l}\text { The historical ties between donor and recipient country has } \\
\text { influenced the donors to give more aids to recipient government }\end{array}$ \\
\hline & Good governance & $\begin{array}{l}\text { Funders direct aid to most of the countries with good governance: } \\
\text { existence of transparency, accountability and less corruption }\end{array}$ \\
\hline & $\begin{array}{l}\text { Recipient government } \\
\text { priorities }\end{array}$ & $\begin{array}{l}\text { Aid Recipient governments have developed their priorities in aid } \\
\text { allocation including burden of diseases, low GDP per capital/poverty, } \\
\text { hard to reach areas, population size }\end{array}$ \\
\hline & $\begin{array}{l}\text { Democratic regimes } \\
\text { and respect for } \\
\text { political and civil rights }\end{array}$ & $\begin{array}{l}\text { The existence of multiparty democracy, respect, and protection of } \\
\text { political and civil rights in the recipient countries have attracted } \\
\text { some donor countries and organizations to allocate more aid to } \\
\text { these countries }\end{array}$ \\
\hline & $\begin{array}{l}\text { Donor foreign policy } \\
\text { goals }\end{array}$ & $\begin{array}{l}\text { Aid allocation has also based on strategic importance of the } \\
\text { recipient countries }\end{array}$ \\
\hline \multirow{3}{*}{$\begin{array}{l}\text { Dimension II } \\
\text { Health needs based } \\
\text { on assessment of } \\
\text { implementing } \\
\text { agencies } \\
\text { Humanitarian } \\
\text { concerns } \\
\text { Recipient }\end{array}$} & $\begin{array}{l}\text { Implementing } \\
\text { partners' interests }\end{array}$ & $\begin{array}{l}\text { Implementing partners have own interests on which areas they } \\
\text { would like to work such as health, education, environment and } \\
\text { agriculture }\end{array}$ \\
\hline & Humanitarian concern & $\begin{array}{l}\text { Commitment of implementing agents to alleviate poverty by } \\
\text { investing in social and economic sectors }\end{array}$ \\
\hline & $\begin{array}{l}\text { Recipient government } \\
\text { directives e.g. burden } \\
\text { of diseases }\end{array}$ & $\begin{array}{l}\text { The recipient government provide guidance and directives on } \\
\text { priority areas for the implementation of various health interventions } \\
\text { including burden of diseases }\end{array}$ \\
\hline
\end{tabular}




\begin{tabular}{|c|c|c|}
\hline $\begin{array}{l}\text { government's } \\
\text { directives }\end{array}$ & & \\
\hline \multirow{5}{*}{$\begin{array}{l}\text { Dimension III } \\
\text { Health needs based } \\
\text { on aid recipient } \\
\text { (government ) needs }\end{array}$} & Burden of diseases & $\begin{array}{l}\text { The under-five mortality rate }\left(\mathrm{U}_{5} \mathrm{MR}\right) \text { is used as an appropriate } \\
\text { proxy for burden of disease }\end{array}$ \\
\hline & Poverty & $\begin{array}{l}\text { Health resources is allocated to the special needs of the poor } \\
\text { population }\end{array}$ \\
\hline & Population size & $\begin{array}{l}\text { Areas with more high population receive more allocation of } \\
\text { resources }\end{array}$ \\
\hline & Hard to reach areas & $\begin{array}{l}\text { Those parts of the country that have physical, communication, social } \\
\text { and economic conditions that make them receive a level of public } \\
\text { service that is relatively inequitable. }\end{array}$ \\
\hline & Vulnerable populations & $\begin{array}{l}\text { These include the economically disadvantaged social groups } \\
\text { including women, children, the elderly, those with human } \\
\text { immunodeficiency virus (HIV), and those with other chronic health } \\
\text { conditions }\end{array}$ \\
\hline $\begin{array}{l}\text { Dimension IV } \\
\text { Health needs based } \\
\text { on thirteen priorities } \\
\text { of the Council } \\
\text { Comprehensive } \\
\text { Health plan }\end{array}$ & Thirteen priority areas & $\begin{array}{l}\text { Medicines, medical equipment, medical and diagnostic supplies } \\
\text { management; Maternal, New-born and Child Health; Communicable } \\
\text { Disease Control; Non - Communicable Disease Control; Treatment } \\
\text { and care of Neglected Tropical Diseases and local priority; } \\
\text { Environmental Health and Sanitation; Strengthen Organizational } \\
\text { Structures and institutional capacities at all levels; Social Welfare } \\
\text { and Social Protection; Strengthen Human Resources for Health } \\
\text { Management Capacity for improved health services delivery; } \\
\text { Emergency Preparedness and Response; Health Promotions; } \\
\text { Traditional and Alternative Medicine; Construction, rehabilitation } \\
\text { and Planned Preventive Maintenance of physical Infrastructures of } \\
\text { Health facilities }\end{array}$ \\
\hline
\end{tabular}

The strengths of this study are use of triangulation in data collection by including key informants interviews and document reviews as well as involving the multidisciplinary research team in peerdebriefing sessions to reflect and discuss procedures and interpretations of the data. This study has two major limitations: the selection of one region limits the generalisability of the findings. However, this region was purposively selected because it is among the regions in Tanzania, which receive allocation of funds from various development partners. This study also suffered another limitation - development partners may have been less likely to discuss how their own interests influenced their choices when selecting geographic and programmatic areas for their programs. However, notwithstanding these limitations, findings from this region provide some insights on the criteria used by the development partners in committing funds in the health sector. Future studies covering more regions and districts are needed to provide a broader picture of how development partners allocate funds to the health and other sectors.

In conclusion, our work, and that of others, has shown that lack of coordination between development partners and recipient governments may lead to managerial problems, including duplication of efforts and inequitable allocation of funds. Development partners, policy makers and programme managers should develop good coordination mechanisms, such as establishing forums where they can regularly meet and discuss the interest and priorities of each stakeholder so as to harmonize them and facilitate the implementation of development partner funded activities in the recipient countries. At the district level, development partners, including those implementing vertical programmes and council health management teams, should work together during the planning stage of Comprehensive Council Health Plans (CCHP) to ensure that all development partner supported activities are incorporated in the CCHP. In so doing, the aid recipient government and district health systems will manage to achieve the expected health outcomes, including enhancing quality of health service delivery as well as equity in accessing health services.

\section{Competing interest}


Authors of this manuscript work as faculty at Muhimbili University of Health and Allied Sciences in Tanzania and John Hopkins University in USA. All authors declare that they have no any competing interest.

\section{Acknowledgements}

This study was supported by USAID through the Health Research Challenge for Impact (HRC) Cooperative Agreement (\#GHS-A-00-09-00004-00). The authors would like to acknowledge the contributions and cooperation of the study participants (programme managers and District Reproductive and Child Health Coordinators) who gave their time to be interviewed. The authors would also like to thank the qualitative data collection field team, in particular Ms. Aisha Omary, who worked together with authors to conduct interviews; MUHAS-based team consisting of Dr. Charles Kilewo, Dr. Rose Mpembeni, Dr. David Urassa, the Jhpiego-based team consisting of Ms. Maryjane Lacoste, Dr. Chrisostom Lipingu, Dr. Miriam Kombe, Ms. Elaine Charurat, Ms. Chelsea Cooper; and the JHSPH-based team consisting of Ms. Carla Blauvelt, Dr. Asha George, Dr. Shivam Gupta, Dr. Amnesty Lefevre, Ms. Nicola Martin, and Dr. Diwakar Mohan, Raz Stevenson at United States Agency for International Development, Dar es Salaam, Tanzania, Neal Brandes and Troy Jacobs at USAID Washington .

\section{References}

Afnan-Holmes, H., Magoma, M., John, T., Levira, F., Msemo, G., Armstrong, C. E., ... Lawn, J. E. (2015) Tanzania's Countdown to 2015: an analysis of two decades of progress and gaps for reproductive, maternal, newborn, and child health, to inform priorities for post-2015. Lancet Global Health 3(7): e396-e409.

Bandyopadhyay, S., \& Wall, H.J. (2006) The Determinants of Aid in the Post-Cold War Era. Working Paper No. 2006-021B (Vol. 1). St. Louis, MO 63166.

Chen, L.-W., Jacobson, J., Roberts, S., \& Palm, D. (2012) Resource allocation and funding challenges for regional local health departments in Nebraska. Journal of Public Health Management and Practice 18: 141-147.

Conyers, D., \& Mellors, R. (2005) Aid Ineffectiveness in Sub-Saharan Africa: The Problem of Donor Capacity. Political Studies 36: 83-89.

Feeny, S. \& McGillivray, M. (2008) What Determines Bilateral Aid Allocations? Evidence From Time Series Data. Review of Development Economics 12: 515-529.

Lawson, M.L. (2012) Foreign aid: International donor coordination of development assistance. In Globalization: Background, Agreements and Current Issues (pp. 73-94).

Maizels, A. \& Nissanke, M. (1984) Motivations for aid to developing countries. World Development 12: 879-900.

Mapunda, M. (2003) Towards Partnership in Health Experiences in resource allocation in Tanzania, focusing on Sector Wide Approach (SWAp) and Health Basket Fund. Bulletin of Medicus Mundi Switzerland No 91.

McKinley, R.D. \& Little, R. (1979) The US aid relationship: a test of the recipient need and the donor interest models. Political Studies 27: 236-250.

Michaud, C. \& Murray, C.J. (1994). External assistance to the health sector in developing countries: a detailed analysis, 1972-90. Bulletin of the World Health Organization 72: 639-651.

Neumayer, E. (2003) Do human rights matter in bilateral aid allocation? A quantitative analysis of 21 donor countries. Social Science Quarterly 84: 650-666.

OECD (2005) Paris Declaration on Aid Effectiveness. Paris, France.

OECD (2006) Aid Effectiveness: Three Good Reasons Why the Paris Declaration Will Make a Difference. http://www.oecd.org/dac/effectiveness/31451637.pdf 
Piva, P. \& Dodd, R. (2009) Where did all the aid go? An in-depth analysis of increased health aid flows over the past 10 years. Bulletin of the World Health Organization 87: 930-939.

Radhakrishna, R.B. (2007) Tips for Developing and Testing Questionnaires/Instruments. Journal of Extension 45(1).

Rotarou, E. \& Ueta, K. (2009) Foreign Aid and Economic Development : Tanzania's Experience with ODA, 78(December), 157-189.

Schieber, G., Fleisher, L. \& Gottret, P. (2006) Getting Real on Health Financing. A Quarterly Magazine of the IMF 43: 1-10.

Semali, I.A. \& Minja, G. (2005) Deprivation and the equitable allocation of health care resources to decentralised districts in Tanzania Regional. EQUINET (No. 33).

Shiffman, J. (2006) Donor funding priorities for communicable disease control in the developing world. Health Policy and Planning 21: 411-420.

Thompson, D.S., Estabrooks, C.A., Scott-findlay, S., Moore, K. \& Wallin, L. (2007) Implementation Science. International Encyclopedia of Social \& Behavioral Sciences 16: 1-16.

Tripp, A. M. (2012) Donor Assistance and Political Reform in Tanzania. Working Paper No . 2012 / 37. UNU World Institute for Development Economics Research (UNU-WIDER) Helsinki, Finland, 2012.

URT (2008) The National Road Map Strategic Plan to Accelerate Reduction of Maternal, Newborn and Child Deaths in Tanzania 2008 - 2015. Dar es Salaam, United Republic of Tanzania.

URT (2009) Tanzania Mainland National Accounts 2009/2010. Dar es Salaam, United Republic of Tanzania.

URT (2011) Comprehensive Health Planning Guidelines. Dar es Salaam, United Republic of Tanzania.

URT (2013) 2012 Population and Housing Census: Population Distribution by Age and Sex. National Bureaus of Statistics, Dar es Salaam, Tanzania.

Victora, C.G., Huicho, L., Amaral, J.J., Armstrong-Schellenberg, J., Manzi, F., Mason, E. \& Scherpbier, R. (2006) Are health interventions implemented where they are most needed? District uptake of the integrated management of childhood illness strategy in Brazil, Peru and the United Republic of Tanzania. Bulletin of the World Health Organization 84: 792-801.

WHO (2010) A Framework for National Health Policies, Strategies and Plans. Geneva, Switzerland.

Zinnen, V. (2010) Sector-Wide Approach (SWAP) as support to Health Sector reforms and results at operational level in rural environment in Tanzania. Catholique de Louvain, Bruxelles, Belgium. 